\title{
Global microRNA profiles and signaling pathways in the development of cardiac hypertrophy
}

\author{
H.J. Feng ${ }^{1}$, W. Ouyang ${ }^{1}$, J.H. Liu ${ }^{1}$, Y.G. Sun ${ }^{1}$, R. Hu ${ }^{1}$, L.H. Huang ${ }^{1}$, J.L. Xian ${ }^{1}$, \\ C.F. Jing ${ }^{2}$ and M.J. Zhou ${ }^{2}$ \\ ${ }^{1}$ Department of Nuclear Medicine, Zhujiang Hospital, Southern Medical University, Guangzhou, China \\ ${ }^{2}$ National Engineering Research Center, South China Sea Marine Biotechnology, Sun Yat-Sen University, Guangzhou, China
}

\begin{abstract}
Hypertrophy is a major predictor of progressive heart disease and has an adverse prognosis. MicroRNAs (miRNAs) that accumulate during the course of cardiac hypertrophy may participate in the process. However, the nature of any interaction between a hypertrophy-specific signaling pathway and aberrant expression of miRNAs remains unclear. In this study, Spague Dawley male rats were treated with transverse aortic constriction (TAC) surgery to mimic pathological hypertrophy. Hearts were isolated from TAC and sham operated rats $(n=5$ for each group at $5,10,15$, and 20 days after surgery) for miRNA microarray assay. The miRNAs dysexpressed during hypertrophy were further analyzed using a combination of bioinformatics algorithms in order to predict possible targets. Increased expression of the target genes identified in diverse signaling pathways was also analyzed. Two sets of miRNAs were identified, showing different expression patterns during hypertrophy. Bioinformatics analysis suggested the miRNAs may regulate multiple hypertrophy-specific signaling pathways by targeting the member genes and the interaction of miRNA and mRNA might form a network that leads to cardiac hypertrophy. In addition, the multifold changes in several miRNAs suggested that upregulation of rno-miR-331*, rno-miR-3596b, rno-miR-3557-5p and downregulation of rno-miR-10a, miR-221, miR-190, miR-451 could be seen as biomarkers of prognosis in clinical therapy of heart failure. This study described, for the first time, a potential mechanism of cardiac hypertrophy involving multiple signaling pathways that control up- and downregulation of miRNAs. It represents a first step in the systematic discovery of miRNA function in cardiovascular hypertrophy.
\end{abstract}

Key words: Cardiac hypertrophy; Signaling pathway; Biomarker

\section{Introduction}

Heart failure is the major cause of morbidity in the elderly (1). Cardiac hypertrophy is an adaptive process of various cardiovascular disorders including heart failure (2). The major identifying characteristic of cardiac hypertrophy is the abnormal growth of cardiomyocytes, which leads to heart failure and even sudden death $(3,4)$. MicroRNAs (miRNAs) are short noncoding RNAs that negatively regulate gene expression at the posttranscriptional level, providing a novel mechanism of gene regulation $(5,6)$. Some miRNAs are specifically present in certain tissues or cell types such as the heart, while others not restricted to the heart can also have heartspecific roles. For example, miR-1, miR-133a and miR$133 \mathrm{~b}$, which are highly expressed in the skeletal muscle and in the heart, are induced and function during muscle differentiation (7). However, several open questions remain regarding miRNAs and their role in cardiac hypertrophy. 1) What is the fine-expression pattern of miRNAs during pathological hypertrophy? 2) Which miRNAs are involved in cardiac hypertrophy-specific signaling pathways? 3) How do miRNAs interact with these signaling pathways? To better understand the relationships between miRNAs and cardiac hypertrophyspecific signaling pathways, transverse aortic constriction (TAC) surgery was performed in rats to identify cardiac hypertrophy-specific miRNAs using an miRNA microarray screening approach. The relevant miRNA/mRNA signaling pathways were also analyzed using bioinformatics tools.

Correspondence: W. Ouyang, Department of Nuclear Medicine, Zhujiang Hospital, Southern Medical University, 253 Gongyedadao Road, Guangzhou, 510282, China. Fax: +86-20-6164-3473. E-mail: oyw88@tom.com 


\section{Material and Methods}

\section{Animal preparation}

Sprague Dawley male rats (6-8 weeks old, 200-300 g) were housed at $20 \pm 2{ }^{\circ} \mathrm{C}$ and $55 \pm 20 \%$ humidity with $12-\mathrm{h}$ light/dark cycles and free access to food and water in the Animal Care Facility at the Sun Yat-Sen University (SYSU) School of Medicine. This study was approved by the Laboratory Animal Ethics Committee of Sun Yat-Sen University Life and Science School (Guangzhou, China). The investigation conformed to the Guide for the Care and Use of Laboratory Animals published by the China National Institute of Health.

\section{TAC}

To construct a left sided pressure-overload hypertrophy animal model, the rats $(n=20)$ were subjected to TAC surgery. Rats were anesthetized with barbital sodium administered intraperitoneally at $200 \mathrm{mg} / \mathrm{kg}$ body weight. An incision approximately $2 \mathrm{~cm}$ long was made from the level of the cricoid process and dissected to the clavicle. After cutting the right clavicle, the thymus was retracted gently to expose the aortic arch. A constriction of the aortic arch was made between the carotid arteries using an 18-gauge angiocatheter. Sham operated rats $(n=20)$ underwent a similar surgical procedure without constriction of the aorta. After TAC surgery, the chest was closed with a 5-0 nylon suture, and the rats were placed on a heating pad at $37^{\circ} \mathrm{C}$ until they had completely recovered from anesthesia.

\section{Evaluation of cardiac hypertrophy in vivo}

The rat cardiac hypertrophy model was evaluated by histopathology. Five rats were sacrificed with an overdose of pentobarbital $5,10,15$, and 20 days after TAC surgery, The hearts were carefully isolated, heart and body weights measured and the ratios of heart to body weight (HW/BW) were calculated. The hearts were then fixed in $4 \%$ paraformaldehyde, dehydrated, embedded in paraffin, sectioned and stained with hematoxylin and eosin (H\&E). Five rats were sacrificed on each of the 5-day intervals after sham surgery on the same schedule as above. The hearts were collected and processed in the same way as the TAC samples.

\section{MicroRNA microarray assay}

Total RNA was isolated from hearts at 5, 10, 15, and 20 days after TAC or sham surgery using TRIzol (Invitrogen Life Technologies, USA) and an miRNeasy Mini kit (QIAGEN, USA) according to the manufacturers' instructions. RNA quality and quantity were measured using a Nanodrop spectrophotometer (ND-1000, Thermo Fisher Scientific, USA), and RNA integrity was determined by denaturing agarose gel electrophoresis.

After RNA isolation from the hearts, $1 \mu \mathrm{g}$ of each sample was $3^{\prime}$-end-labeled with a $\mathrm{Hy}^{\mathrm{TM}}$ fluorescent label
(Exiqon, Denmark) using T4 RNA ligase. After the labeling procedure, the $\mathrm{Hy}_{3}{ }^{\mathrm{TM}}$-labeled samples were hybridized to an miRCURY'TM LNA Array (v.16.0, Exiqon), which contains more than 1891 capture probes covering all of the human, mouse and rat miRNAs annotated in miRBase 16.0 , as well as all viral miRNAs related to these species. The entire datasets (for miRNAs) described here are available from the Gene Expression Omnibus (GEO, http://www.ncbi.nlm.nih.gov/geo/) through the accession number GSE38599.

\section{Data analysis}

The images on the microarray chip were scanned and imported into the GenePix Pro 6.0 software (Axon; http:// axon-genepix-pro.software.informer.com/) for grid alignment and data extraction. The replicates were averaged, and miRNAs with intensities $>50$ in all samples were used to calculate the normalization factor. Gene expression data were normalized using the median normalization and differentially expressed miRNAs were identified by foldchange filtering (fold-change $\geq 2$ ). Hierarchical clustering was performed using the MeV software (v4.6, TIGR; http://www.tm4.org/mev.html).

\section{Bioinformatics analysis}

Potential targets of the identified miRNAs were analyzed using an online algorithmic prediction program, miRMap 2.0 (http://miRNAMap.mbc.nctu.edu.tw/), which collected the results from multiple miRNA target prediction programs and filtered them according to the following criteria: targets located in the $3^{\prime}$-UTR region, seed length of at least $7 \mathrm{bp}$, and $\mathrm{P}<0.05$. The prediction programs included in miRMap were miRanda, miRDB, miRWalk, RNAhybrid, TargetScan, PITA, RNA22, and DIANA-mT. The inclusion of multiple programs could increase the accuracy of the predicted targets. The predicted target genes were enriched using the KEGG orthology-based annotation system (KOBAS) (http://kobas.cbi.pku.edu.cn/ home.do)

\section{Statistical analyses}

Multiple comparisons between experimental groups were made by analysis of variance followed by the Dunnett test. $\mathrm{P}<0.05$ was considered to be significant.

\section{Results}

\section{Physiological characteristics of hypertrophy}

To validate whether the hypertrophic animal model was constructed successfully, H\&E-stained histological sections were evaluated, and the ratio $\mathrm{HW} / \mathrm{BW}$ in grams was calculated. In the sham group, the myocyte histology was within the normal range, the nuclei were small and thin, and the muscle fibers aligned regularly (Figure 1A; Sham). In response to TAC, after 5 days, the cardiac muscle cells underwent hypertrophic growth without 


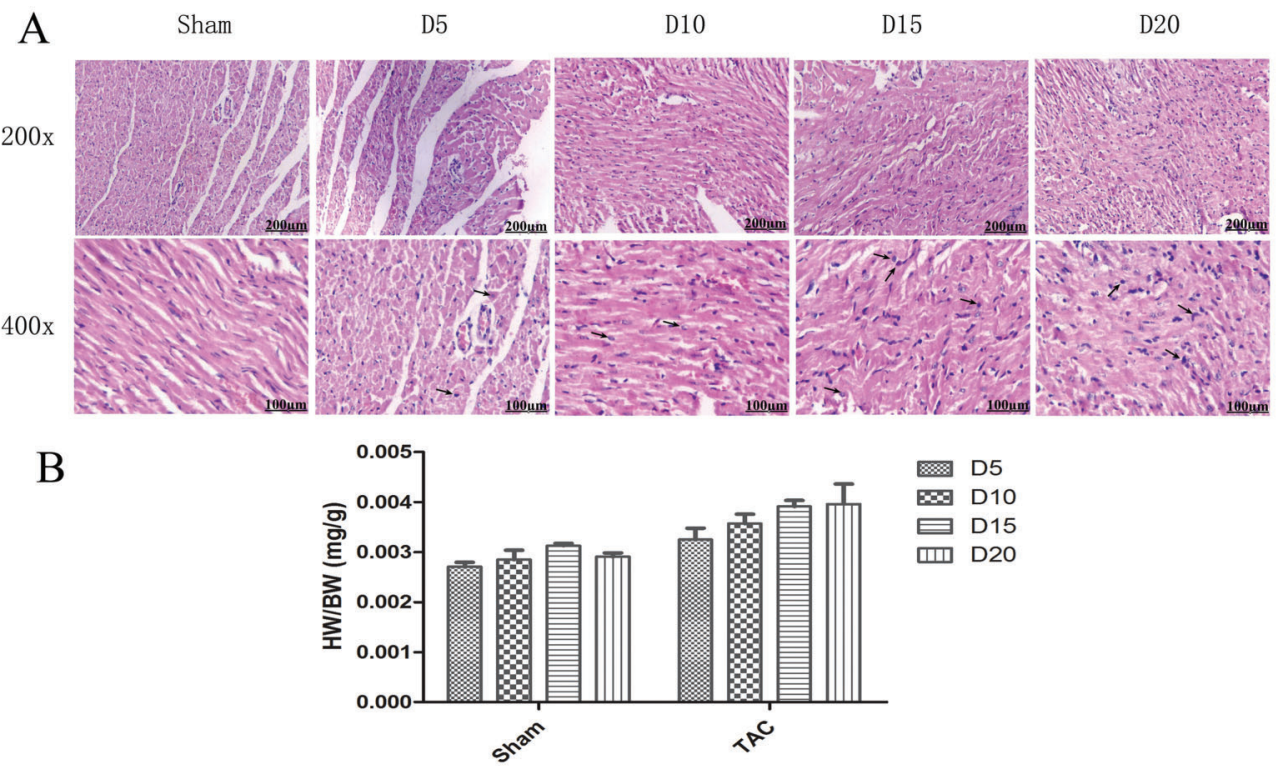

Figure 1. Histopathological characteristics of a rat model of cardiac hypertrophy. $A, \mathrm{H} \& \mathrm{E}$ stained cross-sections of transverse aortic constriction (TAC)-treated and sham-treated rat hearts. Arrows indicate myocardial hypertrophy. $B$, Ratios of heart weight to body weight (HW/BW, mg/g) after TAC and sham surgeries. D: day.

increase in the cell number (Figure 1A; D5). The heart showed a pronounced and continuous increase in cardiac mass accompanied by the hypertrophic growth of cardiomyocytes and ventricular fibrosis at 15 days after TAC surgery (Figure 1A; D15); the remodeling process was also confirmed in hearts isolated at 20 days after surgery (Figure 1A; D20). The process of heart remodeling was accompanied by an increase in the HW/BW ratio. After TAC treatment, the heart weight relative to body weight increased steadily, while that of the sham group did not (Figure 1B). This result showed that hypertrophic growth occurred in this rat model.

\section{Global miRNA expression profile during cardiac hypertrophy}

To identify miRNAs that were spatiotemporally expressed during cardiac hypertrophy, we conducted a comprehensive miRNA microarray analysis of samples from rat hearts that were subjected to TAC or sham operation. Hearts were isolated from rats at $5,10,15$, and 20 days post-TAC or sham operation ( $n=5$, each). Of the 769 miRNAs on the microarray chip, 260 were differentially expressed (Figure 2). The miRNAs that exhibited a $\geq 2$-fold difference in expression in the TAC compared with the sham groups were selected for analysis. The seed lengths of the miRNAs and the identities of the target genes, as well as the associated $P$ values, are reported in Supplementary Files 1 and 2. Upregulated and downregulated miRNAs and downregulated miRNAs during the 20 days after TAC surgery are shown in Tables 1 and 2, respectively. The upregulated miRNAs might be required for the development of hypertrophy. Some miRNAs increased immediately after TAC surgery, including miR331*, miR-3596b, miR-3557-5p, and miR-375. Their expression increased 15 - to 48 -fold at day 5 post-TAC surgery. Meanwhile, several miRNAs were observed to increase dramatically at day 20 after TAC treatment. For example, the expression of rno-miR-221* was below the detection level on day 5 , but increased significantly on day 20 after TAC. Similar results were observed for rno-miR34c. At the same time, the downregulated miRNAs might be less required for the development of hypertrophy; the expression of several miRNAs was observed to decrease dramatically at day 20 after TAC. For example, the expression of miR-190 and miR-451 downregulated immediately to 2.6 and $6.6 \%$, respectively, compared with sham-operated controls on day 5 post-TAC surgery. miR-352 and miR-98 downregulated to 39.2 and $56.6 \%$ compared with controls, respectively, on day 20 .

\section{Comprehensive prediction of miRNA targets and signaling pathway analysis}

Using miRNAMap 2.0, we analyzed the potential targets of miRNAs that are differentially expressed during hypertrophy, with the criteria that the miRNAs must bind the 3'-UTR of the mRNA with longest stretch of base pairing, have a seed length of at least $7 \mathrm{bp}$ and a $\mathrm{P}<0.05$. The prediction programs included miRanda, miRDB, miRWalk, RNAhybrid, and TargetScan/TargetScanS. After strict prediction, the targets were enriched using the KOBAS software to identify the most significantly represented signaling pathways. The identified pathways 


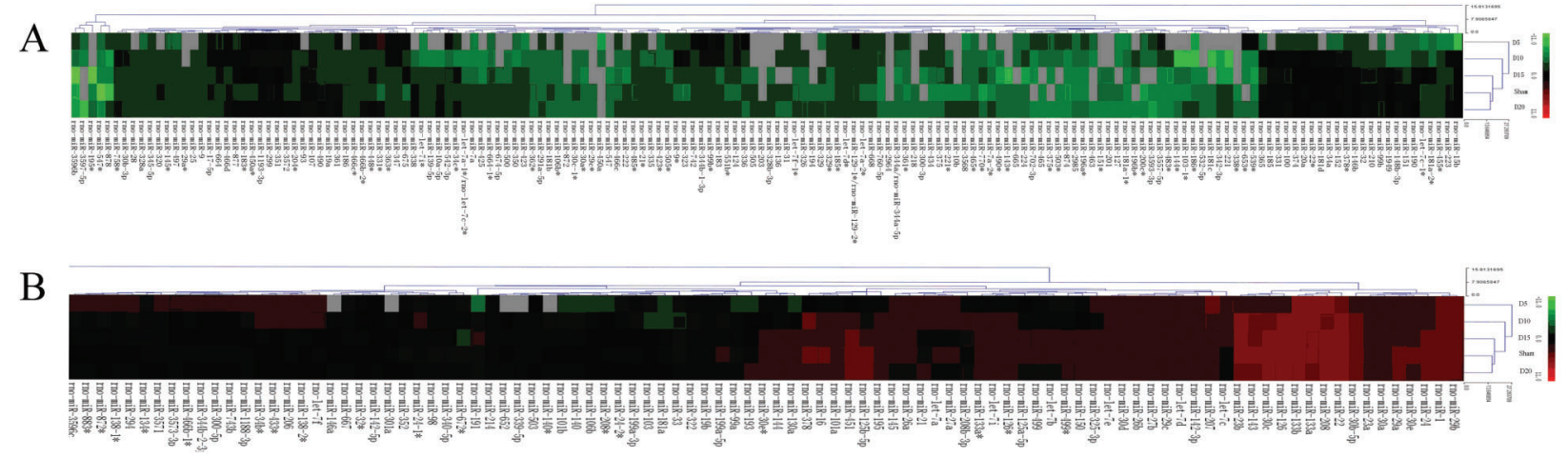

Figure 2. Heat maps of the global expression of miRNAs during hypertrophy. $A$, Upregulated miRNAs; $B$, downregulated miRNAs during hypertrophy.

included the MAPK, JAK/STAT, Calcineurin/NFAT, WNT, apoptosis, heterotrimeric G-protein signaling ( $\mathrm{Gq}$ alphaand Go alpha-mediated pathway), and the renin-angiotensin system (RAS) signaling pathways, all of which have previously been reported to play a role in the development of hypertrophy. The upregulated and downregulated miRNAs, their targets, and the involved signaling pathways are reported in Supplementary Tables S1-S7.

\section{Discussion}

Role played by miRNAs in cardiac hypertrophy through modulating various signaling pathways

Many diseases are characterized by an abnormal miRNA expression pattern. In the field of cardiovascular biology, a multitude of research emphasizes the profound role of miRNAs in cardiovascular diseases. Stressregulated miRNAs can trigger either a positive or a negative influence on the hypertrophic growth response. A number of reports have demonstrated pathological processes such as cardiac remodeling to result from the activation or repression of genes encoding proteins that regulate cardiac contractility and structure (8). Hence, identification of signals and pathways that miRNAs interfere with is important for understanding of the mechanism of hypertrophy and rational design of future drugs for heart failure therapy (9). Previous publications demonstrated that miR-1 and miR-133 belong to the same transcriptional unit and play a critical role in cardiomyocyte hypertrophy. The inhibition of miR-133 caused significant cardiac hypertrophy (10). Here we found that miR-133 was involved in MAPK, RAS and Gq signaling by targeting different genes. Downregulation of miR-1 is necessary for the relief of growth-related target genes from repression (11) and induces hypertrophy (12); miR-1 downregulates calcium-calmodulin signaling through calcineurin to nuclear factor of activated T-cells (NFAT) (13), which was also confirmed with our data. Furthermore, by using bioinformatics, we found that miR-1 was involved in the MAPK, JAK/STAT and Gq signaling pathways.

Apoptosis can be initiated by a variety of miRNAs, and functional studies reported that miR-101 and miR-125b are able to inhibit apoptosis (14), suggesting that these two miRNAs are less required during hypertrophy. miR101 and miR-29b exert their proapoptotic function via targeting of Mcl-1 (15). The expression patterns of the miR-101, miR-29b, and miR-125b isoforms in the present study were consistent with this observation. Furthermore, these two miRNAs participated in the MAPK, JAK/STAT, apoptosis, WNT and calcineurin/NFAT signaling pathways by negatively regulating different targets, which could offer some clues of the detailed mechanism of apoptosis signaling during hypertrophy.

miRNAs could interact with several signaling pathways. MiR-195 is known to be upregulated during hypertrophy, which is consistent with the findings of others. The cardiac overexpression of miR-195 in vivo can drive cardiac hypertrophy that rapidly transitions to heart failure (8). However, the mechanism by which miR-195 promotes hypertrophy is not well understood. In the present study, miR-195 potentially targeted several genes that are involved in multiple signaling pathways, i.e., the Gadd45g, Map2k1, Mras, and Raf1 genes, which are involved in the MAPK signaling pathway. Meanwhile, miR195 targets the Irak2 gene, which is involved in apoptosis signaling, and the Rock1 gene, which is involved in WNT signaling. These findings suggest potential mechanisms underlying the pathological role of miR-195 during hypertrophy.

MiR-499 in cardiac stem cells has been shown to enhance cardiomyogenesis in vitro and after infarction in vivo, which indicates that it can enhance myocyte differentiation/hypertrophy (16). Another study found that increased miR-499 in human and murine cardiac hypertrophy and cardiomyopathy is sufficient to cause murine heart failure and accelerates maladaptation to pressure overloading (17). These findings are similar to our results showing that the expression of miR-499 increased after 
Table 1. Upregulated miRNAs during heart hypertrophy in rats.

\begin{tabular}{|c|c|c|c|c|}
\hline & D5 & D10 & D15 & D20 \\
\hline rno-miR-221* & $\mathrm{N} / \mathrm{A}$ & 2.136 & 15.784 & 13.023 \\
\hline rno-miR-34c & $\mathrm{N} / \mathrm{A}$ & $\mathrm{N} / \mathrm{A}$ & N/A & 9.164 \\
\hline rno-miR-330* & $\mathrm{N} / \mathrm{A}$ & N/A & 1.278 & 9.110 \\
\hline rno-miR-487b* & $\mathrm{N} / \mathrm{A}$ & 4.864 & 10.364 & 7.191 \\
\hline rno-miR-103-1* & $\mathrm{N} / \mathrm{A}$ & $\mathrm{N} / \mathrm{A}$ & 0.322 & 7.049 \\
\hline rno-miR-340-3p & 1.146 & 1.481 & 2.118 & 5.067 \\
\hline rno-miR-17-1-3p & $\mathrm{N} / \mathrm{A}$ & $N / A$ & $\mathrm{~N} / \mathrm{A}$ & 3.473 \\
\hline rno-miR-139-5p & $\mathrm{N} / \mathrm{A}$ & $\mathrm{N} / \mathrm{A}$ & 2.301 & 3.408 \\
\hline rno-miR-29b-2* & $\mathrm{N} / \mathrm{A}$ & $\mathrm{N} / \mathrm{A}$ & $\mathrm{N} / \mathrm{A}$ & 3.215 \\
\hline rno-miR-10a-5p & $\mathrm{N} / \mathrm{A}$ & $\mathrm{N} / \mathrm{A}$ & N/A & 2.623 \\
\hline rno-miR-218 & $\mathrm{N} / \mathrm{A}$ & $\mathrm{N} / \mathrm{A}$ & $\mathrm{N} / \mathrm{A}$ & 2.170 \\
\hline rno-miR-221 & $\mathrm{N} / \mathrm{A}$ & $N / A$ & $\mathrm{~N} / \mathrm{A}$ & 1.781 \\
\hline rno-miR-485* & $\mathrm{N} / \mathrm{A}$ & $\mathrm{N} / \mathrm{A}$ & $\mathrm{N} / \mathrm{A}$ & 1.741 \\
\hline rno-miR-877 & $\mathrm{N} / \mathrm{A}$ & $\mathrm{N} / \mathrm{A}$ & $\mathrm{N} / \mathrm{A}$ & 1.600 \\
\hline rno-miR-142-5p & $\mathrm{N} / \mathrm{A}$ & N/A & $\mathrm{N} / \mathrm{A}$ & 1.558 \\
\hline rno-miR-193 & $\mathrm{N} / \mathrm{A}$ & $\mathrm{N} / \mathrm{A}$ & $\mathrm{N} / \mathrm{A}$ & 1.245 \\
\hline rno-miR-34c & N/A & $\mathrm{N} / \mathrm{A}$ & N/A & 9.164 \\
\hline rno-miR-331* & 47.647 & 5.043 & 4.638 & 6.067 \\
\hline rno-miR-3596b & 22.496 & 6.727 & 0.095 & 2.017 \\
\hline rno-miR-3557-5p & 17.390 & 4.404 & 0.957 & 0.821 \\
\hline rno-miR-375 & 15.492 & 16.400 & 4.137 & 3.537 \\
\hline rno-miR-434 & 13.977 & 6.096 & 1.770 & 2.616 \\
\hline rno-miR-1249 & 12.120 & 4.000 & 3.586 & 5.374 \\
\hline rno-let-7c & 9.895 & 6.633 & 3.938 & 1.604 \\
\hline rno-miR-363* & 7.649 & 3.511 & 1.605 & 1.655 \\
\hline rno-miR-874 & 7.020 & 1.393 & 1.494 & 1.791 \\
\hline rno-miR-3541 & 6.996 & 2.684 & 1.817 & 1.574 \\
\hline rno-miR-347 & 6.933 & 5.291 & 1.564 & 1.452 \\
\hline rno-miR-3571 & 6.709 & 3.205 & 3.149 & 1.243 \\
\hline rno-miR-465 & 6.695 & 2.122 & $\mathrm{~N} / \mathrm{A}$ & 0.984 \\
\hline rno-miR-743b & 6.336 & 2.139 & 1.733 & 1.656 \\
\hline rno-miR-551b* & 6.322 & 6.355 & 2.204 & 1.937 \\
\hline rno-miR-138-2* & 5.415 & 2.515 & 1.109 & 0.947 \\
\hline rno-miR-138-1* & 5.309 & 1.919 & 1.607 & 1.490 \\
\hline rno-miR-124 & 4.661 & 4.901 & 1.727 & 2.215 \\
\hline rno-miR-1188-3p & 4.658 & 2.896 & 1.227 & 0.896 \\
\hline rno-miR-34b* & 4.633 & 4.181 & 1.353 & 1.061 \\
\hline rno-miR-3573-3p & 4.563 & 1.994 & 1.529 & 1.221 \\
\hline rno-miR-344b-2-3p & 4.458 & 1.732 & 1.604 & 1.423 \\
\hline rno-miR-344b-1-3p & 4.166 & 2.026 & 1.048 & 0.872 \\
\hline rno-miR-207 & 4.105 & 2.047 & 1.365 & 0.874 \\
\hline rno-miR-872* & 3.856 & 2.129 & 1.291 & 1.245 \\
\hline rno-miR-466b-1* & 3.726 & 1.853 & 1.139 & 1.222 \\
\hline rno-miR-340-5p & 3.567 & 3.036 & 1.570 & 1.159 \\
\hline rno-miR-206 & 3.559 & 2.236 & 1.169 & 0.810 \\
\hline rno-miR-3596c & 3.494 & 1.833 & 1.468 & 1.208 \\
\hline rno-miR-503* & 3.161 & 2.074 & $\mathrm{~N} / \mathrm{A}$ & 0.610 \\
\hline rno-miR-134* & 2.924 & 2.091 & 1.341 & 1.166 \\
\hline rno-miR-294 & 2.815 & 2.458 & 2.002 & 1.382 \\
\hline rno-let-7a & 2.695 & 1.356 & 0.623 & 0.607 \\
\hline rno-miR-667 & 2.514 & 1.554 & 1.369 & 1.077 \\
\hline
\end{tabular}

Continued in next column
Table 1. Continued.

\begin{tabular}{lclll}
\hline & D5 & D10 & D15 & D20 \\
\hline rno-miR-21 & 2.422 & 2.046 & 0.819 & 1.153 \\
rno-miR-27a $_{\text {rno-miR-181a-1* }}$ & 2.286 & 1.733 & 0.732 & 0.635 \\
rno-miR-194 $^{\text {rno-miR-21* }}$ & 1.361 & 2.302 & 1.362 & 1.056 \\
& 1.320 & 1.231 & 1.936 & 2.656 \\
\end{tabular}

Data are reported as the ratios of miRNA microarray signals between TAC and sham-operated animals. N/A: not applicable; D: day.

TAC surgery. The bioinformatics analysis indicated that miR-499 might interfere with WNT, JAK/STAT, and apoptosis signaling pathways during the development of hypertrophy. miR-23 and miR-24 were recently shown to be upregulated in hypertrophic and ischemic cardiomyopathy (18), which show similar expression patterns, and were predicted in this study to regulate MAPK and WNT signaling.

Surprisingly, miRNAs and signaling pathways could interact in the development of pathological hypertrophy through gene targeting. Improved knowledge of this network provides a better understanding of the fine mechanisms involved in hypertrophy and heart failure. More importantly, these findings could potentially be translated into pharmacological therapies for the treatment of various cardiac diseases that are adversely affected by hypertrophy (2).

\section{Novel potential biomarkers contribute to the prognosis of cardiac disorders}

The profile of miRNA expression is dependent on the disease state as specific pathological processes are often associated with a particular gene expression pattern. These signature patterns can aid in the diagnosis and prognosis in cardiovascular diseases (19). miR-21, miR$34 \mathrm{~b} / \mathrm{c}$, miR-27a, and miR-181a have been shown to regulate cell stress and proliferation processes (20). In previous publications $(11,21-23)$, miR-10a, miR-221, miR1, miR-101, miR-451, and miR-133 were shown to be downregulated during hypertrophy. Using a high-throughput miRNA microarray method in this study, the expression of most of the miRNAs mentioned above was found to increase. miR-133 is expressed specifically in cardiomyocytes, miR-133 knockout mice develop severe fibrosis and heart failure (24). The decreased expression of miR-1 and miR-133 observed in present study is consistent with previous reports $(25,26)$, which demonstrates the reliability and accuracy of our data, and our analyses provide hypothetical mechanistic explanations for some previously unexplained observations, although experimental validation is still required.

Moreover, the current study highlights the large 
Table 2. Downregulated miRNAs during heart hypertrophy in rats.

\begin{tabular}{|c|c|c|c|c|}
\hline miRNAs & D5 & D10 & D15 & D20 \\
\hline rno-miR-29a* & $\mathrm{N} / \mathrm{A}$ & N/A & 0.385 & 1.000 \\
\hline rno-miR-1949 & $\mathrm{N} / \mathrm{A}$ & 0.052 & 0.665 & 0.925 \\
\hline rno-miR-425 & $\mathrm{N} / \mathrm{A}$ & 0.145 & 0.280 & 0.921 \\
\hline rno-miR-93 & $\mathrm{N} / \mathrm{A}$ & 0.711 & 0.950 & 0.916 \\
\hline rno-miR-342-3p & $\mathrm{N} / \mathrm{A}$ & 0.066 & 0.092 & 0.848 \\
\hline rno-miR-210 & $\mathrm{N} / \mathrm{A}$ & 0.261 & 0.615 & 0.836 \\
\hline rno-miR-3585-5p & $\mathrm{N} / \mathrm{A}$ & $\mathrm{N} / \mathrm{A}$ & 0.380 & 0.800 \\
\hline rno-miR-500 & $\mathrm{N} / \mathrm{A}$ & 0.195 & 0.444 & 0.789 \\
\hline rno-miR-143* & $\mathrm{N} / \mathrm{A}$ & $\mathrm{N} / \mathrm{A}$ & 0.091 & 0.772 \\
\hline rno-miR-328b-3p & $\mathrm{N} / \mathrm{A}$ & $\mathrm{N} / \mathrm{A}$ & 0.341 & 0.772 \\
\hline rno-miR-547 & $\mathrm{N} / \mathrm{A}$ & $\mathrm{N} / \mathrm{A}$ & 0.321 & 0.765 \\
\hline rno-miR-186 & $\mathrm{N} / \mathrm{A}$ & 0.474 & 0.533 & 0.757 \\
\hline rno-miR-505 & $\mathrm{N} / \mathrm{A}$ & $\mathrm{N} / \mathrm{A}$ & 0.359 & 0.748 \\
\hline rno-miR-674-3p & $\mathrm{N} / \mathrm{A}$ & $\mathrm{N} / \mathrm{A}$ & $\mathrm{N} / \mathrm{A}$ & 0.731 \\
\hline rno-miR-140* & $\mathrm{N} / \mathrm{A}$ & 0.501 & 0.628 & 0.700 \\
\hline rno-let-7a-1*/rno-let-7c-2* & $\mathrm{N} / \mathrm{A}$ & 0.203 & 0.420 & 0.654 \\
\hline rno-miR-10a-5p & $\mathrm{N} / \mathrm{A}$ & 0.034 & 0.490 & 1.736 \\
\hline rno-miR-221 & $\mathrm{N} / \mathrm{A}$ & 0.017 & 0.061 & 1.136 \\
\hline rno-miR-222 & $\mathrm{N} / \mathrm{A}$ & 0.303 & 0.124 & 0.842 \\
\hline rno-miR-133a & 1.266 & 1.458 & 1.057 & 0.829 \\
\hline rno-miR-1 & 1.057 & 0.873 & 0.943 & 0.894 \\
\hline rno-miR-133b & 0.963 & 1.152 & 1.057 & 0.823 \\
\hline rno-miR-98 & 0.830 & 0.794 & 0.577 & 0.566 \\
\hline rno-miR-352 & 0.791 & 0.570 & 0.640 & 0.392 \\
\hline rno-miR-19a & 0.696 & 0.414 & 0.539 & 1.030 \\
\hline rno-miR-23a & 0.536 & 0.525 & 0.716 & 0.905 \\
\hline rno-miR-29a & 0.526 & 0.671 & 0.732 & 0.827 \\
\hline rno-let-7i & 0.386 & 0.694 & 0.852 & 0.921 \\
\hline rno-miR-19b & 0.356 & 1.137 & 0.931 & 0.960 \\
\hline rno-miR-103 & 0.347 & 0.292 & 0.744 & 0.836 \\
\hline rno-miR-140 & 0.344 & 0.520 & 0.653 & 0.751 \\
\hline rno-miR-101b & 0.318 & 0.417 & 0.647 & 0.757 \\
\hline rno-miR-22 & 0.275 & 0.567 & 0.912 & 0.926 \\
\hline rno-miR-106b & 0.258 & 0.635 & 0.807 & 0.904 \\
\hline rno-miR-145* & 0.250 & 0.613 & 0.887 & 0.835 \\
\hline rno-miR-24-2* & 0.248 & 0.392 & 0.576 & 0.619 \\
\hline rno-miR-100 & 0.232 & 0.710 & 0.527 & 0.569 \\
\hline rno-miR-32 & 0.181 & 0.480 & 0.678 & 0.899 \\
\hline rno-miR-181a & 0.160 & 0.198 & 0.740 & 0.637 \\
\hline rno-miR-30e* & 0.155 & 0.212 & 0.798 & 0.798 \\
\hline rno-miR-16 & 0.137 & 0.664 & 0.685 & 0.822 \\
\hline rno-miR-146b & 0.134 & 0.320 & 0.604 & 0.982 \\
\hline rno-miR-101a & 0.133 & 0.484 & 0.870 & 0.953 \\
\hline rno-miR-423 & 0.119 & 0.196 & 0.448 & 0.811 \\
\hline rno-miR-125b-5p & 0.108 & 0.124 & 0.392 & 0.665 \\
\hline rno-miR-195 & 0.094 & 0.542 & 0.808 & 0.831 \\
\hline rno-miR-451 & 0.066 & 0.329 & 0.974 & 0.864 \\
\hline rno-miR-190 & 0.026 & 0.115 & 0.449 & 0.821 \\
\hline
\end{tabular}

Data are reported as the ratios of miRNA microarray signals between TAC and sham-operated animals. N/A: not applicable; D: day. 
number of novel miRNAs that are expressed abnormally in heart tissue during the course of hypertrophy, many of which have not been reported before. Some of these miRNAs undergo multifold changes in different stages of hypertrophy, which highlight the potential of miRNAs as targets for development of diagnostic and prognostic biomarkers and/or for therapeutic purposes. Some miRNAs are potential biomarkers for different stages of cardiovascular disease in clinical diagnoses. As for the highly expressed miRNAs in the early stage of hypertrophy, such as miR-331*, miR-3596b, miR-3557-5p, miR-375, miR-434, miR-1249, the expression of these miRNAs increased dramatically, nearly $12-$ to 48 -fold. Some other microRNAs, such miR-190, miR-451, miR-195, miR-423, were remarkably decreased by nearly 8 - to 38-times the control group levels. These microRNAs could be used as clinical biomarkers of the early stages of hypertrophy. miRNAs highly expressed at the late stage of hypertrophy, such as rno-miR-221*, miR-34c, miR-330*, miR-487b*, miR-103-1*, miR-340-3p, increased dramatically by nearly 5- to 13-fold. Some other microRNAs, such as miR-352, miR-98, miR-100, downregulated $39-57 \%$ of the control group levels. These microRNAs could be used as clinical biomarkers for late stage hypertrophy. The major changes in the expression of these novel miRNAs associated with cardiac hypertrophy provide novel and specific prognostic biomarkers for clinical cardiovascular disease diagnosis.

Both increasing and decreasing expression of miRNAs may be related to the initiation of pathogenic

\section{References}

1. Dettmeyer R, Schmidt P, Kandolf R, Madea B. Evolution of dilated cardiomyopathy (DCM) from idiopathic hypertrophic cardiomyopathy (IHCM) vs inflammatory dilated cardiomyopathy (DCMi): a rare case of sudden death in an 8-year-old boy. Pathol Res Pract 2004; 200: 411-415, doi: 10.1016/ j.prp.2004.03.005.

2. Rohini A, Agrawal N, Koyani CN, Singh R. Molecular targets and regulators of cardiac hypertrophy. Pharmacol Res 2010; 61: 269-280, doi: 10.1016/j.phrs.2009.11.012.

3. Dorn GW, Robbins J, Sugden PH. Phenotyping hypertrophy: eschew obfuscation. Circ Res 2003; 92: 1171-1175, doi: 10.1161/01.RES.0000077012.11088.BC.

4. Aaronson KD, Sackner-Bernstein J. Risk of death associated with nesiritide in patients with acutely decompensated heart failure. JAMA 2006; 296: 1465-1466, doi: 10.1001/jama.296.12.1465.

5. Bartel DP. MicroRNAs: genomics, biogenesis, mechanism, and function. Cell 2004; 116: 281-297, doi: 10.1016/S00928674(04)00045-5.

6. Cuellar TL, McManus MT. MicroRNAs and endocrine biology. J Endocrinol 2005; 187: 327-332, doi: 10.1677/joe. 1.06426 .

7. Oliveira-Carvalho V, Carvalho VO, Silva MM, Guimaraes GV, Bocchi EA. MicroRNAs: a new paradigm in the treatment and diagnosis of heart failure? Arq Bras Cardiol 2012; 98: 362369, doi: 10.1590/S0066-782X2012000400011. processes in heart. Knowledge of the miRNAs that are abnormally expressed during hypertrophy makes in vivo regulation of miRNA levels a feasible therapeutic measure (27). Using anti-miRNAs, i.e., modified antisense oligonucleotides targeting mature miRNA sequence, can reduce the levels of highly expressed miRNAs. Meanwhile, using mimics of mature miRNA can elevate the miRNA levels (28). It has been reported that genetic deletion of miR-208a prevents pathological cardiac remodeling, and using an antisense oligonucleotide to inhibit miR-208a during hypertension-induced heart failure in rats prevented cardiac remodeling and improved survival (29). Anti-miRNAs might also be effective against the highly expressed miRNAs identified in the present study, such as rno-miR-3596b, rno-miR-434, and rnomiR-331*. Significantly, the oligonucleotide-based regulation of miRNAs will soon provide deeper insights into the biological effects that can be used in the fight against hypertrophy-induced heart failure.

\section{Supplementary Material}

Click here to view [pdf]

\section{Acknowledgments}

Research supported by the Guangdong Natural Science Foundation (\#10151051501000036).

8. van Rooij E, Sutherland LB, Liu N, Williams AH, McAnally J, Gerard RD, et al. A signature pattern of stress-responsive microRNAs that can evoke cardiac hypertrophy and heart failure. Proc Natl Acad Sci U S A 2006; 103: 18255-18260, doi: $10.1073 /$ pnas. 0608791103 .

9. Gladka MM, da Costa Martins PA, De Windt LJ. Small changes can make a big difference - microRNA regulation of cardiac hypertrophy. J Mol Cell Cardiol 2012; 52: 74-82, doi: 10.1016/j.yjmcc.2011.09.015.

10. Callis TE, Wang DZ. Taking microRNAs to heart. Trends Mol Med 2008; 14: 254-260, doi: 10.1016/j.molmed.2008. 03.006 .

11. Elia L, Contu R, Quintavalle M, Varrone F, Chimenti C, Russo MA, et al. Reciprocal regulation of microRNA-1 and insulin-like growth factor-1 signal transduction cascade in cardiac and skeletal muscle in physiological and pathological conditions. Circulation 2009; 120: 2377-2385, doi: 10 1161/CIRCULATIONAHA.109.879429.

12. Sayed D, Hong $C$, Chen IY, Lypowy J, Abdellatif M. MicroRNAs play an essential role in the development of cardiac hypertrophy. Circ Res 2007; 100: 416-424, doi: 10. 1161/01.RES.0000257913.42552.23.

13. Ikeda S, He A, Kong SW, Lu J, Bejar R, Bodyak N, et al. MicroRNA-1 negatively regulates expression of the hypertrophy-associated calmodulin and Mef2a genes. Mol Cell Biol 2009; 29: 2193-2204, doi: 10.1128/MCB.01222-08. 
14. Li P. MicroRNAs in cardiac apoptosis. J Cardiovasc Trans/ Res 2010; 3: 219-224, doi: 10.1007/s12265-010-9175-9.

15. Su H, Yang JR, Xu T, Huang J, Xu L, Yuan Y, et al. MicroRNA101, downregulated in hepatocellular carcinoma, promotes apoptosis and suppresses tumorigenicity. Cancer Res 2009; 69: 1135-1142, doi: 10.1158/0008-5472.CAN-08-2886.

16. Hosoda T, Zheng H, Cabral-da-Silva M, Sanada F, IdeIwata N, Ogorek B, et al. Human cardiac stem cell differentiation is regulated by a mircrine mechanism. Circulation 2011; 123: 1287-1296, doi: 10.1161/CIRCULA TIONAHA.110.982918.

17. Matkovich SJ, Hu Y, Eschenbacher WH, Dorn LE, Dorn GW. Direct and indirect involvement of microRNA-499 in clinical and experimental cardiomyopathy. Circ Res 2012; 111: 521-531, doi: 10.1161/CIRCRESAHA.112.265736.

18. Ikeda S, Kong SW, Lu J, Bisping E, Zhang H, Allen PD, et al. Altered microRNA expression in human heart disease. Physiol Genomics 2007; 31: 367-373, doi: 10.1152/physiolgenomics. 00144.2007.

19. Kartha RV, Subramanian S. MicroRNAs in cardiovascular diseases: biology and potential clinical applications. $J$ Cardiovasc Transl Res 2010; 3: 256-270, doi: 10.1007/s12265010-9172-z.

20. Thum T, Galuppo P, Wolf C, Fiedler J, Kneitz S, van Laake LW, et al. MicroRNAs in the human heart: a clue to fetal gene reprogramming in heart failure. Circulation 2007; 116: 258-267, doi: 10.1161/CIRCULATIONAHA.107.687947.

21. Fang $Y$, Shi $C$, Manduchi E, Civelek M, Davies PF. MicroRNA-10a regulation of proinflammatory phenotype in athero-susceptible endothelium in vivo and in vitro. Proc Natl Acad Sci U S A 2010; 107: 13450-13455, doi: 10.1073/ pnas. 1002120107.

22. Smits M, Mir SE, Nilsson RJ, van der Stoop PM, Niers JM,
Marquez VE, et al. Down-regulation of miR-101 in endothelial cells promotes blood vessel formation through reduced repression of EZH2. PLoS One 2011; 6: e16282, doi: 10. 1371/journal.pone.0016282.

23. Zhang $X$, Wang $X$, Zhu $\mathrm{H}$, Zhu $\mathrm{C}$, Wang $\mathrm{Y}$, Pu WT, et al. Synergistic effects of the GATA-4-mediated miR-144/451 cluster in protection against simulated ischemia/reperfusioninduced cardiomyocyte death. $J$ Mol Cell Cardiol 2010; 49: 841-850, doi: 10.1016/j.yjmcc.2010.08.007.

24. Creemers EE, Pinto YM. Molecular mechanisms that control interstitial fibrosis in the pressure-overloaded heart. Cardiovasc Res 2011; 89: 265-272, doi: 10.1093/cvr/cvq 308.

25. Fontana L, Sorrentino A, Condorelli G, Peschle C. Role of microRNAs in haemopoiesis, heart hypertrophy and cancer. Biochem Soc Trans 2008; 36: 1206-1210, doi: 10.1042/BST 0361206.

26. Thum T, Catalucci D, Bauersachs J. MicroRNAs: novel regulators in cardiac development and disease. Cardiovasc Res 2008; 79: 562-570, doi: 10.1093/cvr/cvn137.

27. Krutzfeldt J, Rajewsky N, Braich R, Rajeev KG, Tuschl T, Manoharan $\mathrm{M}$, et al. Silencing of microRNAs in vivo with 'antagomirs'. Nature 2005; 438: 685-689, doi: 10.1038/ nature04303.

28. van Rooij E, Sutherland LB, Qi X, Richardson JA, Hill J, Olson EN. Control of stress-dependent cardiac growth and gene expression by a microRNA. Science 2007; 316: $575-$ 579, doi: 10.1126/science.1139089.

29. Montgomery RL, Hullinger TG, Semus HM, Dickinson BA, Seto AG, Lynch JM, et al. Therapeutic inhibition of miR208a improves cardiac function and survival during heart failure. Circulation 2011; 124: 1537-1547, doi: 10.1161/CIR CULATIONAHA.111.030932. 